\title{
Characterization of metal grades in a stockpile of an Iron Mine (Case study - Choghart iron mine, Iran)
}

The Mining-Geology-Petroleum Engineering Bulletin UDC: 622.1

DOI: $10.17794 / \operatorname{rgn} .2018 .2 .5$

Original scientific paper

\author{
Sara Kasmaee'; Francesco Tinti²; Roberto Bruno ${ }^{3}$ \\ Department of Civil, Chemical, Environmental and Materials Engineering, University of Bologna, via Terracini 28, 40131 Bologna, Italy \\ ${ }^{1}$ Research fellow; ${ }^{2}$ Junior Assistant Professor; ${ }^{3}$ Associate Professor
}

\begin{abstract}
In any mining operation due to the cut-off grade (economic criteria), materials are classified into ore and waste. The material with grade equal to or higher than the cut-off grade is considered as ore and the material with grade less than the cut-off grade is transported as waste to waste dumps. However, because of an increasing metal demand, depletion of in situ ore reserves is occurring and so there is a reduction of cut-off grades for many metals, and the mentioned waste dumps are considered as valuable ore reserves named stockpiles. In this paper, multivariate geostatistics was used to estimate the iron grades of two stockpiles following the sequential piling procedures from the main source - the ore deposit - to the piling field. One stockpile is characterized by phosphorous concentration $((P \%)>0.6 \%)$, while the other by iron concentration $((\mathrm{Fe} \%)<50 \%)$. Since economic and physical constraints made sampling physically and economically problematic, the grade distribution and variability were estimated on the basis of primary blast-hole data from the main ore body and the mine's long-term planning policy. A geostatistical model was applied to the excavated part of the iron deposit and by reconstructing ore selection, the haulage and the piling method. Results were validated through spatial variability of iron and phosphorous concentrations by comparing grade variability (Fe and $P$ ) with mining and piling units. A comparison of the grade variability has shown that with the same variogram models (with a larger range and smaller variance), the spatial variability of stockpiles have followed the variability of the selected part of the ore body. This point can be used to predict the grade variability of stockpiles from the origin source and the methodology allows characterizing the iron grades within stockpiles without any extra sampling.
\end{abstract}

\section{Keywords}

Spatial variability, Linear co-regionalisation model (LMC), Co-kriging (CK), Stockpile

\section{Introduction}

Since the beginning of mining operations, stockpiles are formed by dumping waste or low-grade materials, considered not valuable at the time of excavation. Generally, stockpiles are located beside the open pit area without economic benefits. However, advances in recovery and processing technology have led to the reconsideration of stock materials as a new source for feeding the processing plants. The depletion of the in-situ reserves and an increasing need of using lower grade materials are additional reasons to consider stockpiles as recoverable resources. In fact, the environmental and legal barriers to primary access to mineral resources within and outside of many countries (with particular reference to the European Union) are increasing, leading to a growing economic value of processing secondary raw materials and re-sampling mining stockpiles and other forms of waste disposals (Tiess, 2010, Blengini et al., 2017). Recently, environmental aspects caused a strong push

Corresponding author: Sara Kasmaee

Sara.kasmaeeyazdi2@unibo.it for more the effective management of stockpiles in many mining sites (Lèbre et al., 2017). Some companies and environmental institutes have developed and put on the market proprietary technology allowing tailings and stockpile remediation that is harmless to humans and environmentally friendly (Knight Piésold Cunsulting, 2012). Therefore, these aboveground stockpiles have to be quantified and classified and a reliable expected-revenue model must be developed to assess the feasibility of production.

There are a number of studies applied to stockpiles or tailings due to completely divergent targets (Lèbre et al., 2017, Sracek et al., 2006, Guezennec et al., 2015, Alcolea et al., 2015, Abrosimova et al., 2015, Castillo et al., 2013, Gholamnejad et al., 2012, Kasmaee et al., 2010). Among them, we can mention studies for the characterization of environmental issues of mine wastes, such as evaluation of the acid drainage production potential, related to sulphur mine wastes (Sracek et al., 2006, Guezennec et al., 2015), or characterization of the contaminated mine wastes and their effects on soil or other environmental aspects (Alcolea et al., 2015, Abro- 
simova et al., 2015, Castillo et al., 2013). Moreover, focusing on reutilizing stockpiles as economical sources -which are the direct products of mining procedures before the processing plants -leads to several considerations on characterization of the grade of the minerals that are inside the stockpiles. The cut-off grades are dynamic, changing in time during mining operation (Ataei and Osanloo, 2003, Bascetin and Nieto, 2007, Osanloo et al., 2008, He et al., 2009, Meagher et al., 2014). This implies the existence of low-grade ore stockpiles that, although uneconomical to process in the past years, nonetheless contain sufficient metal grade to justify a second mining and refining later on (King, 2001). Some authors have estimated stockpile grade-tonnage curves from the set of geostatistical simulated ore body realizations in order to establish possible long-term stockpiles (Asad and Dimitrakopoulos, 2012). In other cases, different methodologies are applied on stockpiles to figure out the blending opportunities of the different possibilities for building and reclaiming (Jupp et al., 2013). Moreover, geostatistical simulation methods are applied to optimize stockpile designs using sparse samples. Therefore, the uncertainty at un-sampled locations is estimated by using the distribution of the variables (Kumral, 2006, Marques et al. 2009).

In all the mentioned studies, characterization of the stockpiles requires adequate sampling, if possible by integrating existing data with new sampling. However, according to the sampling problems -the sampling of compact solids and particulate solids- and different errors influenced in the sampling procedure, in the cases with different sizes of materials, errors of samplings may be negatively notable $(\mathbf{G y}, \mathbf{1 9 8 2})$. Hence, sampling in extensive stockpiles containing rocks of different sizes can be cumbersome and costly. Huge stockpile size and the consequent difficulty of access to all parts of piles for sampling, along with grain size variety, are some reasons why sampling may be complicated. However, at the prefeasibility study stage, sampling can be dispensed with numerical modelling using data from the exploited ore body and then reconstructing the piling procedures, namely: ore selection, haulage and piling. The spatial correlation of natural mineralization will be significantly modified with respect to the pilling procedure in the stockpiles, up to disappearing (on the point of the artificial aspect of stockpiles). Hence, stockpiles will show significant disruption to the original spatial correlation of natural mineralization. On the other hand, the time sequence of excavations of blocks and their subsequent piling - or part of them- in nearby locations as stockpiles following the same time order, may lead to, in some way, maintain the natural spatial correlation of the main ore deposit. This is because stockpiles are part natural and part artificial, and they are located starting from the main deposit. Considering this point, initial data must be obtained regarding stockpile grade (as a variable) characterization and selection from the main ore deposit and the stockpiling procedure. The stockpile construction method will determine the spatial variability of the grade. Back reconstruction of the flows of the exploitation of the main resource, the waste selection process, their transportation and disposal can provide predictions regarding stockpile variable distribution and spatial variability inside the stockpile.

In this paper, a study is presented on stockpile grade distribution and their variability estimation based on primary data from the main ore body. The case study is related to two stockpiles in an iron mine (Choghart iron mine-IRAN), where sampling was considered economically and physically unfeasible. The iron and phosphate grade distribution of stockpiles are estimated using geostatistical numerical modelling. The iron and phosphorus grades, contained in a given piling volume - equal to the contents of a single truck - were estimated by CoKriging (CK). Reconstruction of the haulage process allowed calculation of stockpile grade distribution. The scope of this work is studying the possibility of the grade distributions prediction in stockpiles by simulating the piling process at the prefeasibility study.

\section{Materials and methods}

A comparison between the grade spatial variability in stockpile and deposit can be based on the ore, which is sent to stockpiles as a portion of the main deposit, that has been determined by cut-off selection (grade selection). Stockpile grades considered by the procedure; refer to the elementary unit (cell) that constitutes it, in other words, to a not-punctual support, which is the excavation blocks. Reconstruction ore flow from deposit to stockpile requires the identification of an elementary unit (a unique volume named support) of in situ ore corresponding to the piling unit, which is conditioned by the piling process. This work is performed on a case study, two stockpiles from an iron mine in IRAN.

\subsection{Choghart Iron Ore Mine, Iran}

The Choghart ore deposit is located in the region of Bafgh, approximately 125 kilometers $(\mathrm{km})$ southeast of the city of Yazd, Iran (see Figure 1). This mine is operating as an open pit since 1975.

Initially, the Choghart ore body was a prominent iron ore outcrop measuring $800 \mathrm{~m} \times 300 \mathrm{~m}$, standing $150 \mathrm{~m}$ above the surrounding plain, itself some $1257 \mathrm{~m}$ above sea level (Moor and Modabberi, 2003). The iron ore is low in sulphur, with the majority rock-type of non-oxidized (magnetite ore). Over 65\% volume of the reserve is of the low phosphorous type (Torab and Lehman, 2006). However, a huge quantity of high-grade, high phosphorous ore (on average above $0.6 \%$ of phosphorous) and low-grade ore (on average less than $50 \%$ iron) has been removed from the pit and stored in high phosphate $(H P):[F e \% \geq 50 \%, P \geq 0.6]$ and low grade $:(L G)$ 


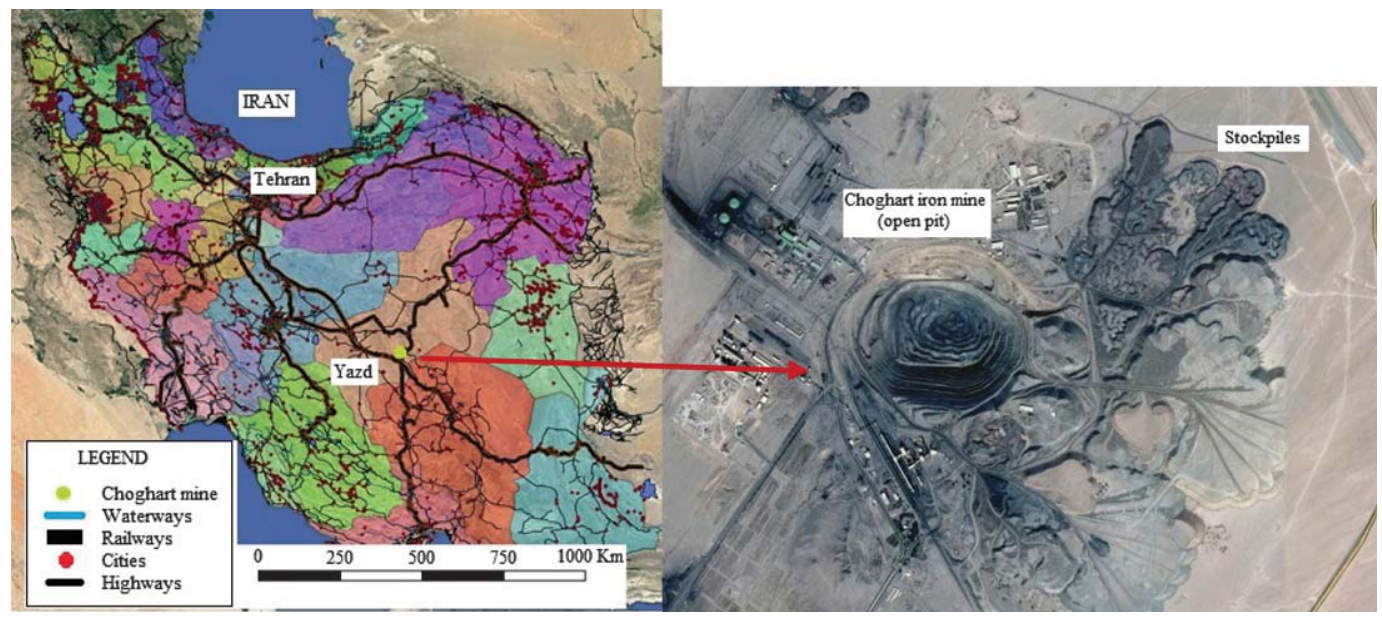

Figure 1: Choghart iron ore mine (a) and stockpile locations (b)

$[\mathrm{Fe}<50 \%]$ stockpiles for possible future beneficiation. The construction of a processing plant at Choghart able to produce 3.2 Mt of iron concentrate has made exploitation of the piles potentially economically viable (Gholamnejad and Kasmaee 2012).

Exploitation at Choghart is open cast, with $10 \mathrm{~m}$ high blasting benches. Each blasting panel is almost $25 \mathrm{~m} \times$ $25 \mathrm{~m} \times 10 \mathrm{~m}$ and blast-holes lie in a regular pattern of 5 $\mathrm{m} \times 5 \mathrm{~m} \times 10 \mathrm{~m}$. The blasted rock is shovelled onto trucks and transferred to a crushing plant. The high phosphorous and low-grade iron ore are transported to separate stockpiles. Open pit operations entail five stages: drilling, blasting, loading, transporting and crushing. Loading and transporting is via a truck- shovel system. The two main - HP and $L G$ - stockpiles were started in 1993 using 35-ton-capacity trucks. Materials have been disposed in sequential horizontal layers, with each stockpile section being filled over 30 days, approximately one month. In both cases, stockpile construction followed all mining plan operations (drilling, blasting, loading and hauling to the two different locations) with the exception of the crushing stage (see Figure 2). For the prefeasibility study of the mine, it is possible for localization of parts of stockpiles from ore deposits. For

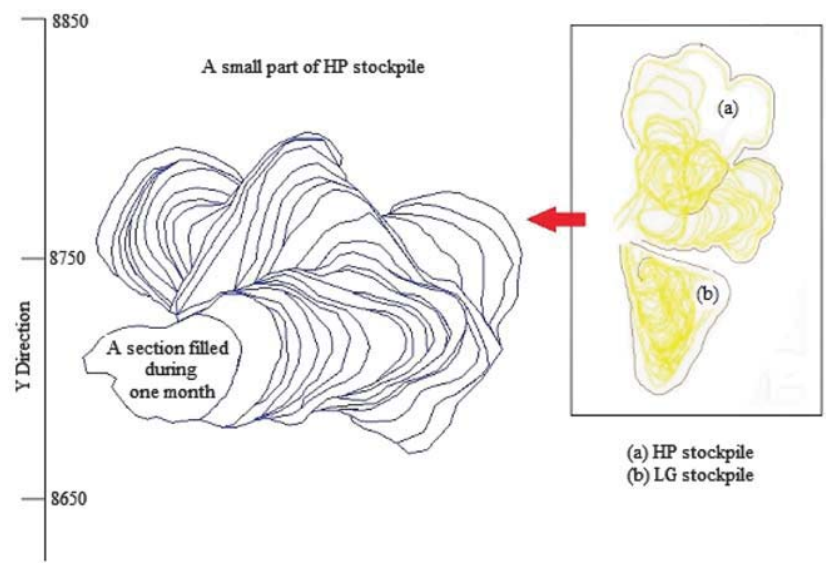

Figure 2: $H P$ and $L G$ stockpiles stockpiles where the part is considered of piling from mines to reconstruct the process.

Each stockpile is almost $400(\mathrm{X}) \mathrm{m} \times 500(\mathrm{Y}) \mathrm{m} \times 20$ (Z) $\mathrm{m}$ and includes rocks with completely different grain size. Their huge size and wide rock grain dimension make sampling both difficult and costly. However, the availability of complete blast-hole data as well as the regular piling sequences from identified mine panels allow reliable prefeasibility studies to be carried out prior to embarking on costly sampling operations.

\subsection{Methodology}

During mine exploitation, parts of the blocks, selected according to the cut-off grade are considered for piling in an area near the pit. The piling procedure can be considered in order to follow grade flow from ore deposit to stockpiles. In particular, exact information from mine selected materials, loading, haulage and dumping in the specific area at piling areas can be considered to reconstruct stockpiles. In Choghart stockpiles, starting from the ore body, selected parts of the blasted panels

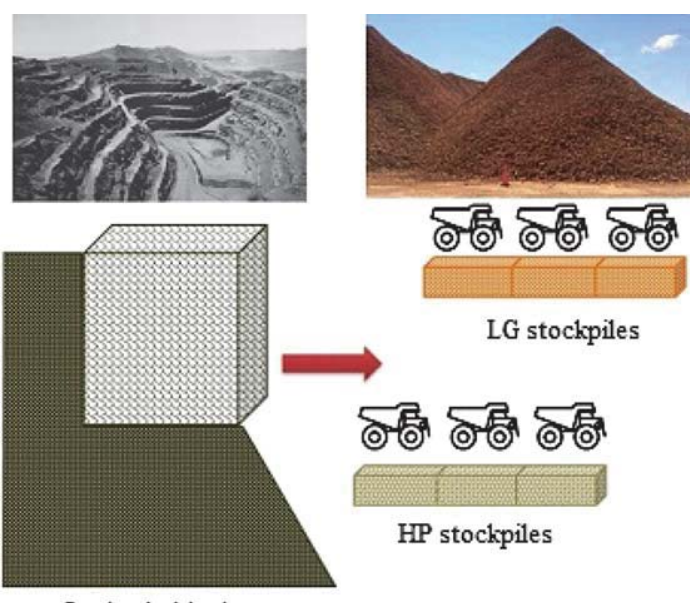

Ore body blocks

Figure 3: Simplified flowchart of piling modelling from ore deposit 
are carried at regular intervals to specific locations within the $H P$ and $L G$ stockpiles and dumped separately, as shown schematically in Figure 3.

For reconstruction of the stockpiles, starting from the ore body, the support- in other words, the elementary volume transported and piled- was considered equal to the trucks capacity (35 ton trucks). Hence, since stockpiles were built up in layers of material from specific areas of the mine, the ore body grade variability should be estimated according to the selected support. Depending on the dimension of the blasted panels in the ore body $(25 \mathrm{~m} \times 25 \mathrm{~m} \times 10 \mathrm{~m})$ and the selected support, the ore-body estimation was considered at block dimension of $2.5 \mathrm{~m} \times 1.4 \mathrm{~m} \times 10 \mathrm{~m}$. These dimensions have been chosen with reference to:

i) bench, the $10 \mathrm{~m}$ height level of the mine to be exploited,

ii) volume, corresponding to truck capacity, and

iii) shovel bucket width

Considering the same support for reconstructing stockpiles, because the elementary stockpile model was conditioned by truck width and height, so considered 1 $\mathrm{m}$ high, $3 \mathrm{~m}$ wide and $4 \mathrm{~m}$ long. Finally, on the basis of the original information and blast-hole samples regularized over a length of $10 \mathrm{~m}$, it was assumed that the 3 cells (as blocks) comprising the same deposit block delivered to the stockpile all with equal grade. The density of Choghart iron rocks were calculated through Equation 1:

$$
S G=0.034 \times(F e \%)+2.34
$$

Where SG is the specific gravity equation that is calculated experimentally from samples and it is used for blocks with stockpile rock-types. Since the stockpiles rocks have low grade $\mathrm{Fe}$ and high grade $P$, the density is low.

Deposit data and spatial analysis of iron and phosphorous grades can be used to assess stockpile characterization. The first step is to make a direct link between deposit and piles according to the selected support. The numerical modelling of the iron distribution of the deposit can be carried out employing the geostatistical method of CK for obtaining block estimates along with estimation variance with selected support. These estimates are further used to predict stockpile grade variability. According to piling process construction, the mean of grades and variance of estimated grades of selected blocks should be constant in the piling procedure, however with some changes with the characterization of spatial variability after moving to the stockpiles. For this idea, it is necessary to evaluate of characterization of concentration ( $\mathrm{Fe}$ and $\mathrm{P}$ ) and tonnage in ore body and then simulating the piling procedure. The stockpiles characterizations can be accomplished through their variograms and cross-variograms (Wackernagel, 2003). According to the piling process, the primary assumption would be increasing the range of variograms from ore

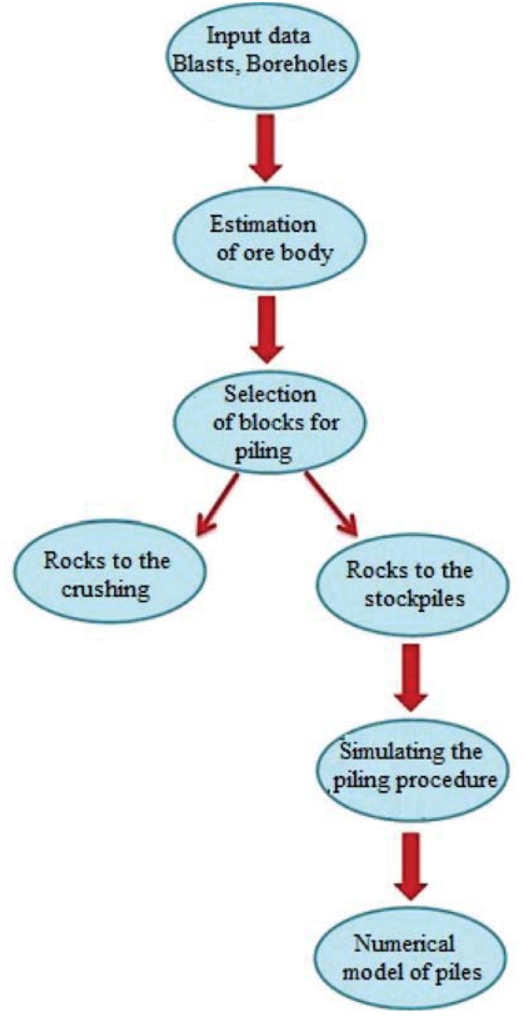

Figure 4: Simple chart of numerical modelling procedure of stockpiles

body to stockpiles (since one block from ore body can fill three cells in stockpiles) but with a decrease in the variance. Figure $\mathbf{4}$ summarizes the used methodology of this study.

\section{Results}

To demonstrate if Choghart stockpiles can follow the characterization of ore body, five blasted panels including blast hole data for low grade and high phosphorous rocks were selected to test the hypothesis. Figure 5

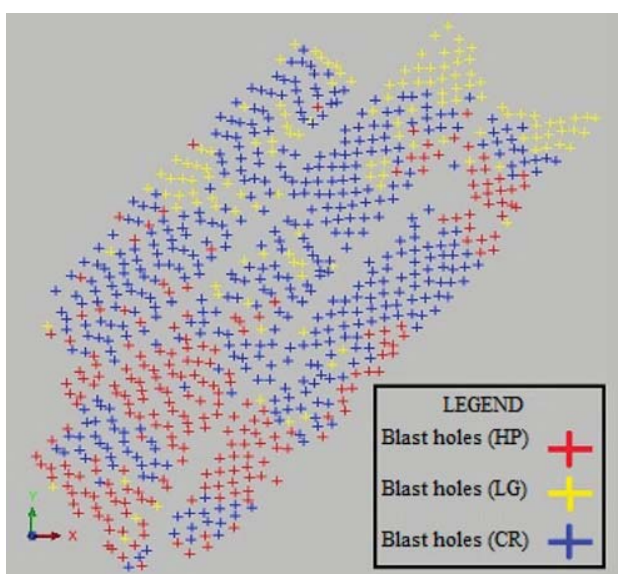

Figure 5: Base map of blast hole data for five panels, classified according destination (High Phosphorous stockpile: Red; Low Grade stockpile: Yellow; Crusher Feed: Blue) at Level $Z=1140 \mathrm{~m}$ above the sea level. 
shows the base map of the selected panels with blasthole samples classified according to feeding destination: crusher $(C R)$ or the different stockpiles $(H P, L G)$.

Conventional statistical data analysis was performed prior to determining the basic characteristics of sampling. Figure 6 shows the summary statistics for $\mathrm{Fe}$ and $P$ distributions, respectively.

Blast hole data of five panels (numbers: 478, 480, 482, 484 and 486) at level $Z=1140 \mathrm{~m}$ (above the sea level) containing low grade $(\mathrm{Fe}<50 \%)$ and high phosphorous $(F e \geq 50 \%, P \geq 0.6 \%)$ were considered as an example. The $F e$ and $P$ grades in the ore body (from mentioned panels) were found to be spatially structured and negatively correlated as shown by the direct and cross variograms (see Figure 7) where a linear co-regionalization model (nugget + exponential with range $20 \mathrm{~m}$ ) was fitted. Depending on block shape - 5 panels (see Figure 5) - the maximum distance of variography was equal to the length of about two panels (less than 100 meters). As
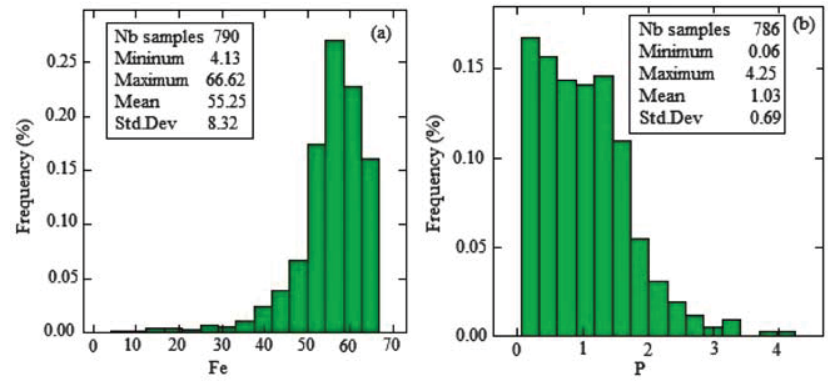

Figure 6: Histograms of $\mathrm{Fe}(a)$ and $P(b)$ concentration (\%) for blast hole data from 5 panels the spatial variability was the same in all the directions, no significant anisotropy was observed in any two directions. Hence, according to the homogeneity of ore body the excavation direction and taking materials would not influence the stockpiles and for spatial variability an omni-directional variogram was used for modelling of the selected zone (five panels).

Since kriging is a linear estimator, it can be expected to be less dispersed than the data (Chiles and Delfiner, 2012); with a lower variogram sill. The cut-off grade criteria modifies means, variances and variogram ranges (Matheron, 1982). Figures 8 and 9 show the direct and cross variograms of a specific portion of the estimated blocks (separated by cut-off for $L G, H P$ ). Note that the sign of the cross-variogram for the blast holes was changed from negative to positive in the case of the cross-variograms of estimated selected blocks in both the $L G$ and $H P$ parts of the ore body. This revealed two different homogeneous populations of iron and phosphorous, which were in fact positively correlated. In addition, it was possible to interpret as the result of the different composition and degree of oxidation, which was the basis for the classification of Choghart iron ore into different groups (Torab, 2008). The stockpile characterization using data from different zones may prove to be quite different from that of one single zone estimated separately.

In fact, in the HP portion of the deposit, the sill of the variogram obtained from block estimated grades shows $\mathrm{P}$ and $\mathrm{Fe}$ to be more homogeneous, with a variance $28 \%$ lower than samples in the $L G$ part of the deposit. Only the $\mathrm{Fe}$ grade had a variogram sill $30 \%$ lower than the
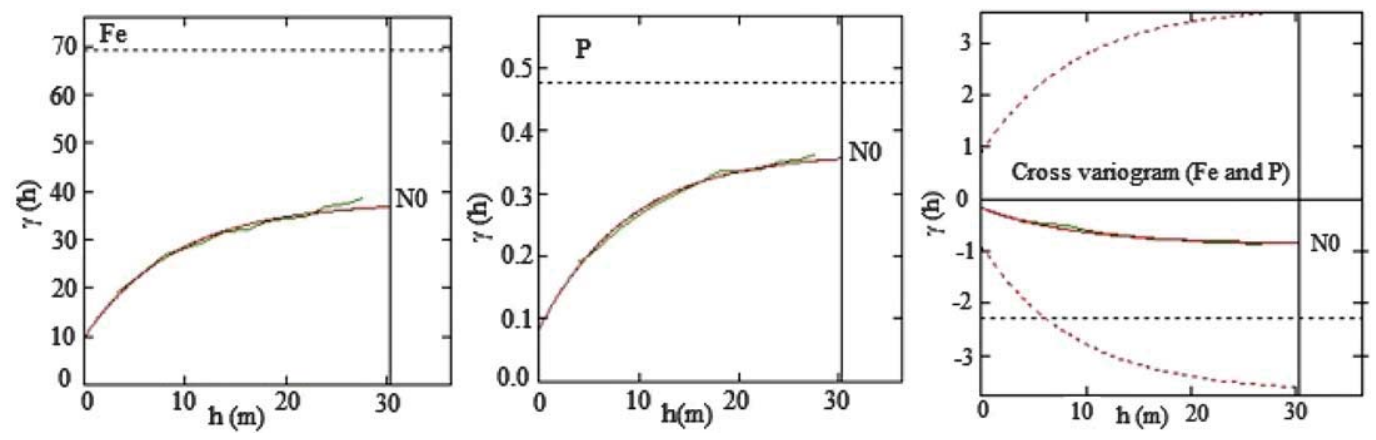

Figure 7: Experimental and cross variograms of $\mathrm{Fe}$ and $P$ obtained from blast holes of five panels
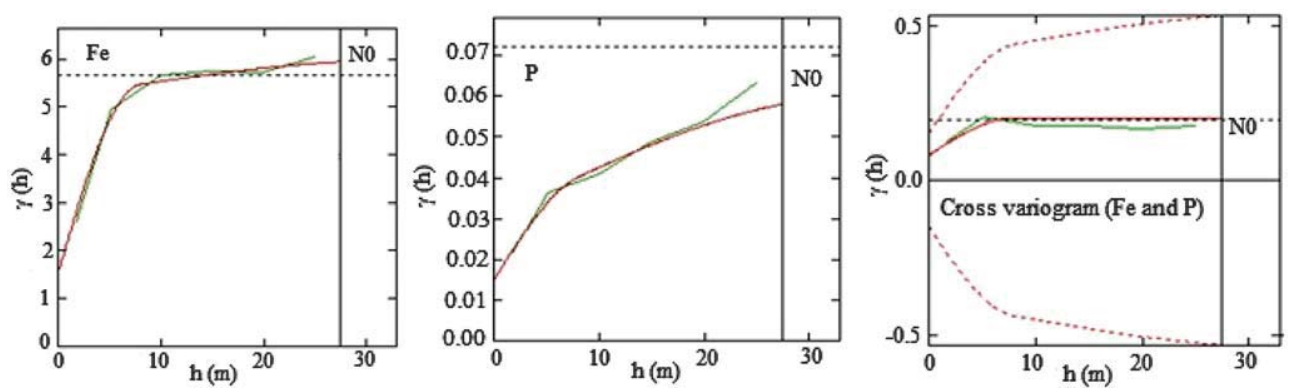

Figure 8: Spatial variability of $H P$ (estimated) blocks from five panels 

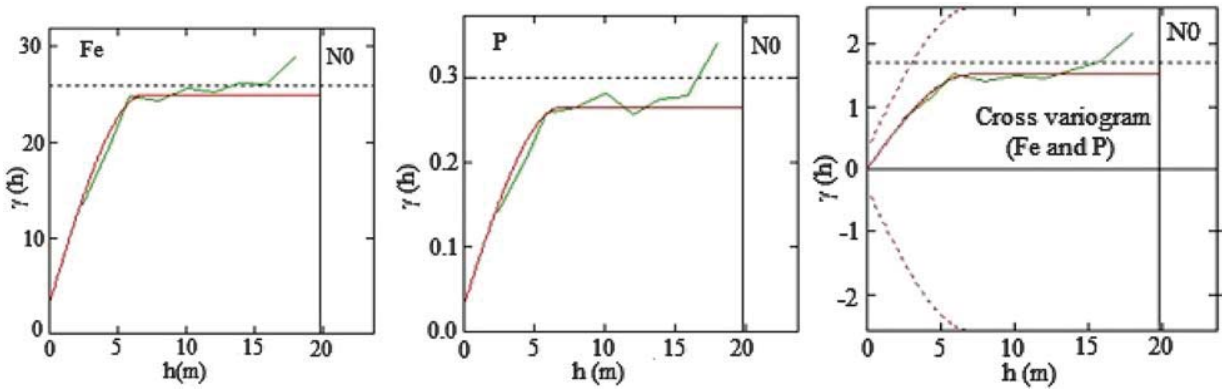

Figure 9: Spatial variability of $L G$ (estimated) blocks from five panels
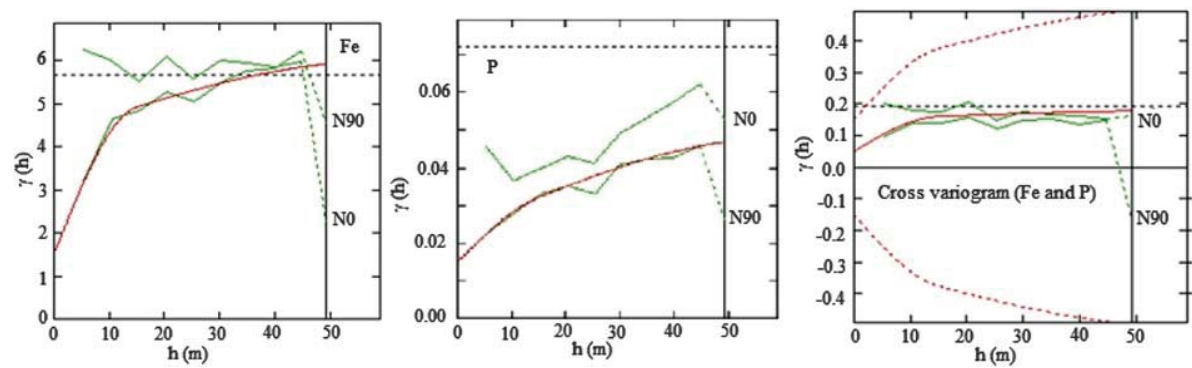

Figure 10: Spatial variability of cells grades of simulated $H P$ pile
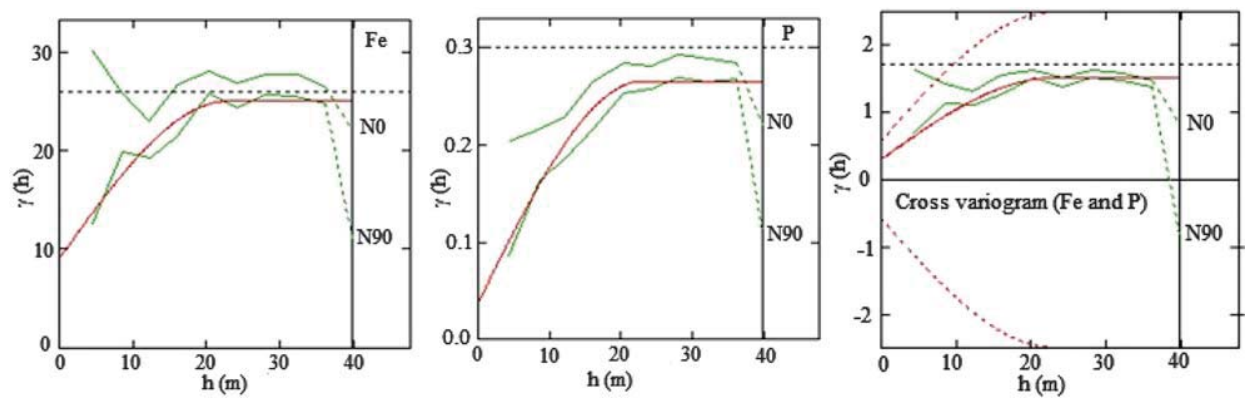

Figure 11: Spatial variability of cell grades of simulated $L G$ pile

variogram obtained from samples, while the $P$ variograms maintained almost the same sill.

Regarding stockpile geometry, construction of the piling procedure considered that a level of stockpile is filled by parallel lines, and when one line is completed, a new line is piled up. When one level was filled, a new level was started. Since the excavated benches had a constant height $(10 \mathrm{~m})$, the heights of each pile sequence (line/level) produced by trucks were also constant $(1 \mathrm{~m})$. Subsequently, grade spatial variability in the reconstructed stockpiles (built up with the same support) can be compared with the specific part of the ore body excavated and transported to the stockpiles (five panels). The experimental and model variograms of piling cell grades along and across the piling directions are shown in Figures 10 and 11. Lag distance for variograms were considered to be about $5 \mathrm{~m}$.

According to the experimental variograms, no orthogonal spatial correlation was found for $\mathrm{Fe}$ in the North-South direction $(\mathrm{NO})$ because of the particular ore disposal process. In contrast, $P$ grades did show some orthogonal spatial correlation to the piling lines, both for $H P$ and $L G$ stockpiles. Further investigation should be carried out to verify and explain this finding, which was probably linked to the long-range structure observed on deposit block grades.

As the main East-West direction (N90) coincided with the direction of stockpile material disposal, stockpile variograms might be expected to have the same spatial behaviour as the main five-panel resource (from ore body) but no orthogonal spatial behaviour. The fact that stockpiles were artificial constructions built up in a series of different layers with selected panels placed in proximity to each other was one of the reasons for the lack of orthogonal structure. The variograms in Figures 10 and 11, show the complete absence of $\mathrm{Fe}$ spatial correlation in direction $N O$ (orthogonal to material disposal). In contrast, $P$ grades in $H P$ and $L G$ stockpiles still maintain some orthogonal spatial correlation to piling lines. In addition, the finding of one ore body panel placed in three stockpile sequences (see Figure 3) requires further investigation and verification of its prob- 
Table 1: comparison of variogram parameters of structured (spherical/spherical) components in stockpiles and deposit blocks

\begin{tabular}{|l|l|l|l|l|l|l|l|l|}
\hline Variogram & Model & Range $(\mathrm{m})$ & Sill-Fe & Sill- $P$ & Sill $F e / P$ & Nugget $F e(\mathrm{~m})$ & Nugget $P(\mathrm{~m})$ & Nugget $F e / P(\mathrm{~m})$ \\
\hline \multirow{2}{*}{$H P$-blocks } & \multirow{2}{*}{ Spherical } & 8 & 3.7 & 0.005 & 0.06 & \multirow{2}{*}{1.5} & \multirow{2}{*}{0.15} & \multirow{2}{*}{0.12} \\
\cline { 3 - 11 } & & 35 & 0.8 & 0.028 & 0 & & \\
\hline \multirow{2}{*}{$H P$-pile } & \multirow{2}{*}{ Spherical } & 15 & 2.8 & 0.008 & 0.1 & 1.5 & 0.15 & 0.05 \\
\cline { 3 - 10 } & & 60 & 1.7 & 0.025 & 0.03 & & 0.03 & 0 \\
\hline$L G$-blocks & Spherical & 7 & 22 & 0.235 & 1.51 & 3 & 0.037 & 0.3 \\
\hline
\end{tabular}

able link to the long-range structure observed (see Figures 10 and 11). Since the regular piling sequences maintained the spatial correlations along the direction of disposal, the range of structures in $H P$ and $L G$ stockpiles increased. To compare the results of spatial variability, the summary of variograms and their models are collected in Table 1.

\section{Discussion}

Numerical modelling of Choghart stockpiles using estimated data from the ore body allowed for the assessment and comparison of piling design sequences with selected parts of the deposit. This modelling technique also produced comparisons of spatial variability of the grade distribution of the main variables $(F e$ and $P$ ) of the two main stockpiles. This can be performed by comparing structural analyses of the stockpiles and main ore body (selected panels) without sampling at the prefeasibility studies. A simple, rapid verification method was a grade spatial variability coherence check between orebody and the stockpiles. Figures $\mathbf{1 0}$ and $\mathbf{1 1}$ showed the results of a check from stockpile cell grade variability. According to the piling process construction, the mean of grades and variance of estimated grades of selected blocks should be constant in the piling procedure. This statement was strongly supported by the study because the results of the CK estimation were directly used for stockpile re-construction. In addition, the horizontal variability along truck discharge lines may be expected to remain unaltered. The same spatial structure was observed within an increased range of a couple of meters and with differentiable behaviour near the origin due to the artificial homogeneity introduced by giving the same grade to three sequential cells in stockpiles. As mentioned in methodology, as expected, variability without spatial correlation (nugget) was in fact observed in the direction orthogonal to piling disposal (see Table 1). This was because when a row was finished, the next one was started either with materials from the same block (now deposited at the initial position) or from a subsequent block. Table 1 showed the proper expectations (or predictions) in the case of spatial structure comparisons.
The exact spherical spatial models were followed with a larger range in the stockpiles (because of materials from one panel of stockpiles were more widely spread out into three larger but thinner layers in stockpiles) (see Figure 3 and Table 1). In the case of $H P$, for example, adding the nugget effect to the sill of the $F e$ variograms in the $H P$ blocks (the HP part of the estimated panels), the variance was equal to 6 (3.7 the first structure sill +0.8 the second structure sill +1.5 nugget effect of $\mathrm{Fe}$ variogram). The result was equal to the $F e$ variance in variograms of the $H P$ stockpile (2.8 the first structure sill + 1.7 the second structure sill +1.5 nugget effect of $\mathrm{Fe}$ variogram). This proved that in this case study; the stockpiles obey the same (spherical) model as the selected part of the deposit, with the same variance and a larger range. The same method can be applied for the $L G$ stockpile with same variance equal to 25 for the $F e$ variable: the $F e$ sill (equal to 22) + nugget effect of $F e$ variogram (equal to 3), in the $L G$ blocks in comparison to the $F e$ sill (equal to 16) + nugget effect of the $F e$ variogram in the $L G$ pile (equal to 9) from Table 1.

This comparison is also applied to $P$ modelling and $\mathrm{Fe} / \mathrm{P}$ cross variograms. Figure 12 shows $\mathrm{Fe}$ distribution in $H P$ and $L G$ stockpiles after piling reconstruction.

By assessing the $\mathrm{Fe}$ variability (\%) in stockpiles, it was possible to mine planning decisions regarding future stockpile excavation, processing feasibility, sampling advisability and the most appropriate excavation site.

Stockpile reserves and grade variability can also be evaluated using the Grade-Tonnage curves. Figure 13 shows the grade-tonnage curves only for $\mathrm{Fe}$ in $L G$ and $H P$ constructed stockpiles. Curves and pile grade variabilities were considered to be of assistance to management decisions regarding sampling with a view to stockpile exploitation and the economic feasibility of waste materials as a new source. According to the Grade-Tonnage curve of the stockpiles, it has shown that with the high demand of raw materials and reducing the cut-off grade of $F e$, both stockpiles can be considered as a new source of $\mathrm{Fe}$, for instance in the cut-off $56 \%$ of $\mathrm{Fe}$, there is 18000 tonnes with the average grade of $\mathrm{Fe}(64.50 \%)$ 

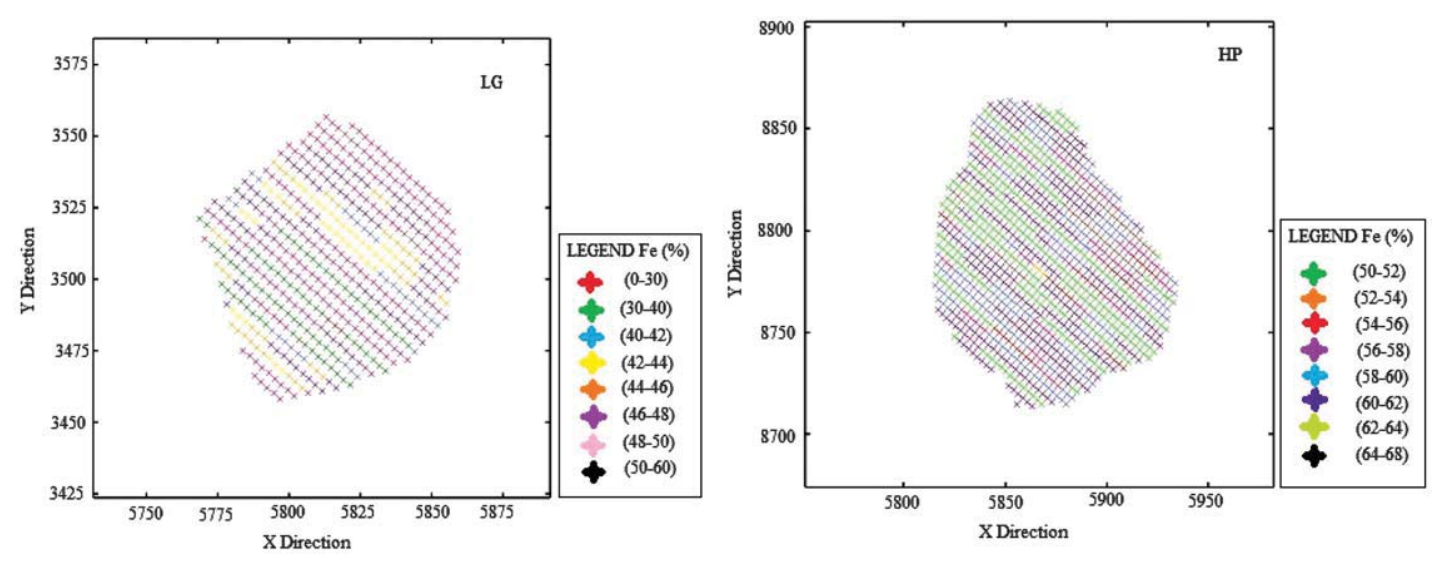

Figure 12: Map of Fe variability (\%) in $H P$ and $L G$ stockpile obtained by construction piling procedure
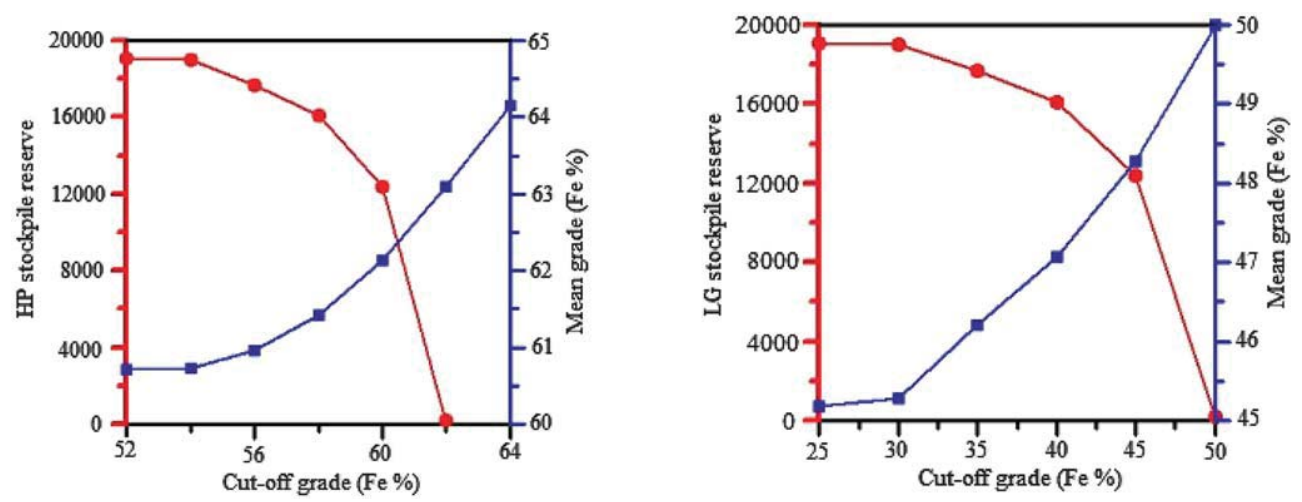

Figure 13: Grade-Tonnage curve for two simulated stockpiles

in the HP stockpile. Therefore, for more precise estimations and economic considerations, sampling of both stockpiles can be reasonable in the future.

\section{Conclusion}

Comparing the results of variogram modelling of piles with the geostatistical parameters of selected blocks from the main deposit allowed an approximation of spatial distribution and variability of pile grade without resorting to extra sampling.

The methodology performed was considering a unique support (trucks capacity), and re-estimating the ore body blocks with multivariate geostatistical methods (linear co-regionalization model). Five blocks of the ore body were selected and studied to evaluate the $F e$ and $P$ grades in stockpiles, according to the sequential piling procedures. Then the characterization of grade variability in stockpiles were studied through their variograms to examine if they could follow the ore body structures. The application proved that, piling sequences are reconstructed exactly by the method, referencing the data of the volumes transported to specific pile locations. According to the piling procedure and the homogeneity of the ore body, the spatial variability of the stockpiles followed the exact models of the ore body with a larger range and a smaller variance than was predicted. The larger range was due to the fact that materials from panels of ore body were widely spread out into larger layers but thinner in stockpiles and the reduced variance was because of the homogeneity of the materials in stockpiles (that were selected from one part of an ore body panel). Hence, for a prefeasibility study, since sampling is difficult and costly, the geostatistical modelling of the $\mathrm{Fe}$ distribution of the deposit can be carried on to predict variability of the ore grade in a stockpile. Moreover, the Grade-Tonnage curves of the stockpiles have shown that with a range of different cut-off grade of $F e$, both stockpiles could be considered as a new source of $\mathrm{Fe}$.

The developed methodology for the reconstruction of ore grades within stockpiles from selected parts of the ore body was implemented in a $\mathrm{VBA}^{\circledR}$ worksheet; it may be of use especially when stockpile sampling is not an immediate or appropriate option. The tool can theoretically be used to regain any kind of primary raw materials and by-products from mining wastes and disposal. This can be particularly valuable for recently important materials for modern industry, such as rare earth elements.

\section{Acknowledgements}

The authors appreciate the insights and help provided by Iran Central Iron Ore Company (ICIOC). Thanks go also to Professor Javad Gholamnejad, manager of the stockpiles project, for kindly providing the data, and to 
Professor Ali Reza Yarahmadi for his assistance in collecting specific and supplementary information.

\section{References}

Abrosimova, N., Gaskova, O., Loshkareva, A., Edelev, A., Bortnikova, S. (2015): Assessment of the acid mine drainage potential of waste rocks at the Ak-Sug porphyry $\mathrm{Cu}-$ Mo deposit, Geochemical Exploration, doi:10.1016/j.gexplo.2015.05.009

Alcolea, A., Fernández-López, C., Vázquez, M., Caparrós, A., Ibarra, I., Garcíac, C., Zarrocad, M., Rodríguez, R. (2015): An assessment of the influence of sulfidic mine wastes on rainwater quality in a semiarid climate (SE Spain), Atmospheric Environment, doi:10.1016/j.atmosenv.2015.02.028

Asad, M.W.A., Dimitrakopoulos, R, (2012): Optimal production scale of open pit mining operations with uncertain metal supply and long-term stockpiles, Resource Policy, doi:10.1016/j.resourpol.2011.12.002

Ataei, M., Osanloo, M, (2003): Methods of calculation of optimal cut off grades in complex ore deposits, Mining Science, 39(5): 499-507, doi:10.1023/B:JOMI.0000029314.42174.d9

Bascetin, A., Nieto, A, (2007): Determination of optimal cutoff grade policy to optimize NPV using a new approach with optimization factor, South African Institute of Mining and Metallurgy, ISSN 0038-223X/3.00 + 0.00

Blengini G.A., Nussa P., Jo Dewulfa J., Nita V., Talens Peirò L., Vidal-Legaza B., Latunussa C., Mancini L., Blagoeva D., Pennington D., Pellegrini M., Van Maercke A., Solar S., Grohol M., Ciupagea C. (2017) EU methodology for critical raw materials assessment: Policy needs and proposed solutions for incremental improvements, Resources Policy, 53, 12-19

Castillo, S., de la Rosa, J.D., Sánchez de la Campa, A.M., González-Castanedo, Y., Fernández-Caliani, J.C., Gonzalez, I, (2013): Contribution of mine wastes to atmospheric metal deposition in the surrounding area of an abandoned heavily polluted mining district (Rio Tinto Mines, Spain), Science Total Environment, 449, 363-372

Chilès, J.P. and Delfiner, P, (2012): Geostatistics: Modeling Spatial Uncertainty. 2rd edition, Wiley, New York, 699 p.

Gholamnejad, J., Kasmaee, S, (2012): Optimum blending of iron ore from Choghart stockpiles by using goal programming, Central South University, 19, 1081-1085, doi: 10.1007/s11771-012-1112-4

Gholamnejad, J., Kasmaee, S, Kohsary, A., Nezamolhosseini, A, (2012): Grade estimation of ore stockpiles by using Artificial Neural Networks: case study on Choghart Iron Mine in Iran, Mining and Mineral Engineering, 4,17-25

Guezennec, A.G., Bru, K., Jacob, J., Hugues, P, (2015): Coprocessing of sulfidic mining wastes and metal-rich postconsumer wastes by bio hydrometallurgy, Minerals Engineering, doi:10.1016/j.mineng.2014.12.033

Gy, PM, (1982): Sampling of Particulate Materials: Theory and Practice, Elsevier Scientific Pub. Co. New York .450 p.

He, Y., Zhu, K., Gao, S., Liu, T., Li, Y, (2009): Theory and method of genetic-neural optimizing cut-off grade and grade of crude ore, Expert Systems with Applications, 4, 7617-7623
Jupp, K., Howard, T.J., Everett, J.E, (2013): Role of pre-crusher stockpiling for grade control in iron ore mining, Applied Earth Science, 122 (4), 242-255,

Kasmaee, S., Gholamnejad, J., Yarahmadi, A., Mojtahedzadeh, H, (2010): Reserve estimation of the high phosphorous stockpile at the Choghart iron mine of Iran using geostatistical modelling, Mining Science and Technology, 20, 855-860,

King, B, (2001): Optimal Mine Scheduling Policies. Dissertation, Royal School of Mines, Imperial College, London University, UK

Knight Piésold Cunsulting, (2012): Waste dumps and stockpiles preliminary design, Ltd.Suite 1400 - 750 West Pender Street, Vancouver, BC V6C 2T8 Canada, Report, 144p

Kumral, O.M, (2006): Bed blending design incorporating multiple regression modelling and genetic algorithms, South African Institute of Mining and Metallurgy, 106, 229-236, ISSN 0038-223X/3.00+0.00

Lèbre E., Glen D., Corder G.D., Golev A., (2017): Sustainable practices in the management of mining waste: A focus on the mineral resource, Minerals Engineering 107, 34-42

Matheron, G, (1982b): La déstructuration des hautes teneurs et le krigeage des indicatrices, Technical Report N.761, Centre de Géostatistique, Fontainebleau, France

Marques, D.M, Costa, J.F., Ribeiro D., Kopp, J.C, (2009): The evidence of volume variance relationship in blending and homogenisation piles using stochastic simulation, in Proceedings of the 4th World Forum on Sampling and Blending, Fourth World Conference on Sampling \& Blending, South African Institute of Mining and Metallurgy, 235-242

Meagher, C., Dimitrakopoulos, R., Vidal, V, (2014): A new approach to constrained open pit pushback design using dynamic cut off grades, Mining Science, 50, 733-744

Moor, F.M, Modabberi, S, (2003): Origin of Choghart Iron oxide deposit, Bafgh Mining district, central Iran: new isotopic and geochemical evidence. Sciences, Islamic Republic of Iran 14(3), 259-269, ISSN 1016-1104

Osanloo, M., Rashidinejad, F., Rezai, B, (2008): Incorporating environmental issues into optimum cut off grades modelling at porphyry copper deposits, Resource. Policy, 33(4), 222-229,

Sracek, O., Gélinas, P., Lefebvre, R., Nicholson, R.V, (2006): Comparison of methods for the estimation of pyrite oxidation rate in a waste rock pile at Mine Doyon site, Quebec, Canada, Geochemical Exploration, 91(1), 99-109Tiess, G., (2010): Minerals policy in Europe: Some recent developments, Resources Policy, 35, 190-198

Tiess, G., (2010): Minerals policy in Europe: Some recent developments, Resources Policy, 35, 190-198

Torab, F.M., Lehman, B.L, (2006): Iron oxide-apatite deposits of the Bafq district, central Iran: an overview from geology to mining, World of Mining-Surface and Underground, Mineralogical Magazine doi:10.1180/minmag.2007.071.3.347

Torab, F.M, (2008): Geochemistry and metallogeny of magnetiteapatite deposits of the Bafq Mining District, Central Iran, Doctoral Thesis, Clausthal University of Technology, Germany, $144 \mathrm{p}$

Wackernagel, H, (2003): Multivariate Geostatistics an Introduction with applications, Berlin, Heidelberg: Springer Berlin Heidelberg, 387 pp. 